Proc. Indian Acad. Sci. (Earth Planet. Sci.), Vol. 90, Number 1, March 1981, pp. 39-46. (C) Printed in India.

\title{
Probable maximum point rainfall estimation for the southern half of the Indian peninsula
}

\author{
O N DHAR, A K KULKARNI and P R RAKHECHA \\ Indian Institute of Tropical Meteorology, Poona 411 005, India
}

MS received 1 August 1980 ; revised 19 December 1980

\begin{abstract}
Preparation of a generalized chart of probable maximum precipitation (PMP) for the southern half of the Indian peninsula lying between lat. $8^{\circ} \mathrm{N}$ to $16^{\circ} \mathrm{N}$ has been attempted in this study. Maximum 1-day rainfall data of 70 to 80 years from 1891 for about 600 stations in the peninsular states of Tamil Nadu, Kerala, South Karnataka and southern portions of Andhra Pradesh were used. In order to get appro riate values of PMP, envelope frequency factor $\left(K_{m}\right)$ curve based on the actual rainfall data of the region was prepared. This study has shown that one-day PMP estimates over this region range from about $25 \mathrm{~cm}$ to about $85 \mathrm{~cm}$. The heavy rainfall received over the coastal areas of Tamil Nadu in association with the cyclonic disturbance of November 1976 was examined and it was found that this rainfall was nowhere near the PMP estimates for this area.
\end{abstract}

Keywords. Probable maximum rainfall ; generalized PMP chart ; cyclonic disturbance.

\section{Introduction}

Planners and design engineers of water resources would like estimates of probable maximum rajnfall (hereafter abbreviated as PMP) for the design of spillway capacities of dams which are to be located up-stream of large towns and industrial areas. In the case of such hydraulic structures no risks regarding their failure can be taken as their failure due to inadequate design would result in tremendous loss of life and destruction of valuable property.

PMP is defined as the highest or the extreme rainfall which is possible over a given point or a specified area for a given duration. It is also defined as the greatest depth of precipitation for a given duration that is physically possible over a given point or an area. In other words, PMP is that magnitude of rainfall which normally should not be exceeded over a very long period of time. Another definition of PMP which is of operational nature states that PMP is that magnitude of rainfall which will yield flood flows of which there is virtually no ris $k$ of being exceeded (Myers 1967).

In recent years, Hershfield (1961) estimated PMP for USA using a statistical technique. Preliminary appraisal of the technique in USA (Myers 1967) and 
Canada (Bruce and Clark 1966) has shown that the PMP estimates obtained by this approach are closely comparable to those obtained by the conventional methods. World Meteorological Organization (WMO) in their various technical publications (WMO 1969, 1970, 1973, 1976) have recommended this method for estimation of extreme rainfall for those river basins whose daily rainfall data are available for a long period of time, but data for storm maximization are lacking. Wiesner (1970) feels that this method has the advantage of taking into account the actual rainfall data, expressing it in terms of statistical parameters and is easy to use. Recently, Mejia and Villegas (1979) have applied this method to stations in Colombia having long-period rainfall data.

In recent years doubts have been expressed whether moisture maximization technique, which has been developed for middle latitudes for obtaining PMP estimates, is also applicable to the tropical regions like India where plentiful supply of moisture is available during the monsoon months. In the absence of any appropriate physical technique which can be applied to the tropical regions, it is felt that the statistical technique of obtaining PMP estimates may be used as this method is based on the actual observed rainfall data of long-period stations in a region. Considering this Dhar and Kulkarni (1970) using the statistical technique (Hershfield 1961,1965$)$ prepared a generalized one-day PMP chart for the plains of north India using about 1000 long-period stations. In the present study an attempt has been made to prepare a similar PMP chart for the southern half of the Indian peninsula, lying between lat. $8^{\circ} \mathrm{N}$ and $16^{\circ} \mathrm{N}$, using 70 to 80 -year rainfall data of about 600 stations.

\section{Hershfield's statistical technique}

Hershfield's (1961, 1965) statistical technique for estimating point PMP has been described by Dhar and Kamte $(1969,1971)$ while determining PMP estimates of Uttar Pradesh. This technique is based on the assumption that information regarding extreme rainfall of a given station or a basin is contained in its long rainfall records.

Hershfield used Chow's (1951) general formula for frequency analysis of extreme values in the following form for obtaining PMP estimates:

$$
X_{\mathrm{PMP}}=\bar{X}_{\mathrm{n}}+S_{n} \cdot K_{\mathrm{m}}
$$

where $\quad X_{\text {Pup }}=$ probable maximum precipitation for a given station, $\bar{X}_{n}=$ mean of the annual maximum rainfall series for that station, $S_{n}=$ standard deviation of the annual maximum series, $n=$ number of years of data, and $K_{m}=$ frequency factor which depends upon the number of years $(n)$ of record and consequently the return period.

Hershfield obtained the $K_{m}$ value by substituting in (1) the highest value $\left(X_{1}\right)$ of the series for $X_{\text {PMr }}$ and worked out $\bar{X}_{n}$ and $S_{n}$ of the series by neglecting the highest value of the series. The $K_{m}$ value was obtained by using the following equation:

$$
K_{m}=\left(X_{1}-\vec{X}_{n-1}\right) / S_{n-1}
$$


where $X_{1}=$ the highest value of the annual maximum rainfall series, $\bar{X}_{n-1}$ and $S_{n-1}$ are mean and standard deviation of the annual maximum rainfall series of $(n-1)$ years of record after excluding the highest value (i.e., $\left.X_{1}\right)$ from the series.

Hershfield worked out $K_{m}$ values for about 2,650 stations in USA and other parts of the world and found the highest value of about 15 for one-day duration. He used this $K_{m}$ value for estimating PMP for different stations of the world.

Several workers (Wilson 1963; Mazumdar and Ranga Rajan 1966) questioned the universal applicability of $K_{m}=15$. It was observed that high values of PMP were obtained if one used the world envelope value of $K_{m}=15$. Dhar and Kamte $(1969,1971,1973)$ have argued that as each meteorological sub-division of India has its own distinct rainfall characteristics, it is reasonable to obtain the $K_{m}$ value for each of these sub-divisions on the basis of their respective long-period rainfall data of stations in each of these regions.

Hershfield (1961) first considered that $K_{m}$ was independant of the rainfall magnitudes. He later found that $K_{m}$ varies inversely with mean of the annual maximum rainfall series (i.e. $\bar{X}_{n}$ ) (Hershfield 1965). Thus, the value of $K_{m}=15$ was found to be high for areas of generally heavy rainfall and low for arid areas (WMO 1973). Subsequently, Hershfield (1965) used the envelope $K_{m}$ curve technique for obtaining $K_{m}$ values for different values of $\bar{X}_{n}$. Dhar and Kamte (1973) have used this approach for preparing a generalized PMP chart of the Brahmaputra basin in northeast India, as this method appears to be quite logical when compared to Hershfield's earlier approach. In the present technique $K_{m}$ value does not depend upon one single highest value of $K_{m}$ in a region but each station has its own $K_{m}$ value depending upon its magnitude of $\bar{X}_{n}$. This modified approach of Hershfield (1965) was adopted in the subsequent PMP studies of north Indian regions of this country (Dhar et al 1975a,b) and this technique has been used to prepare a generalized chart for the southern half of the Indian peninsula.

\section{Reinfall data used}

The maximum one-day point rainfall data covering a period of 70 to 80 years from 1891 for about 600 stations in the peninsular states of Tamil Nadu, Kerala, South Karnataka and southern portions of Andhra Pradesh were used in this study. The number of long-period stations utilized in the present study for each of these states is given below:

Name of the peninsular state

(i) Tamil Nadu

(ii) Kerala

(iii) South Karnataka

(iv) South Andhra Pradesh
Number of long-period rainfall stations used

232

77

200

92

Total $\overline{601}$ 


\section{Analysis of data and procedure used}

The data of yearly observed one-day maximum rainfall for 600 stations were analysed by the procedure given in $\S 2$. The values of $\bar{X}_{n}, \bar{X}_{n-1}, S_{n}, S_{n-1}$ and coefficient of variability (CV) were calculated for all the 600 stations by using the appropriate computer program. The $K_{m}$ values were determined for each station by using (2). These values were then plotted on a large-scale base map of this region and it was found that $K_{m}$ values were randomly distributed and did not show any geographical pattern.

Using the modified technique (Hershfield 1965; WMO 1973), $K_{m}$ values of 600 stations were plotted against $\bar{X}_{n}$ and envelope $K_{m}$ curve for the entire region was drawn. The envelope curve was drawn with the help of three points having maximum $K_{m}$ values and these are shown in figure 1. Before drawing the curve through these points a theoretical curve was also fitted. The equation of the envelope curve, which gives the relationship between the frequency factor $\left(K_{m}\right)$ and the mean annual rainfall $\left(\bar{X}_{n}\right)$, worked out to be $K_{m}=12 \cdot 3 e^{-0.0801 \bar{x}_{n}}$. This equation as well as the curve in figure 1 has been used to obtain $K_{m}$ values

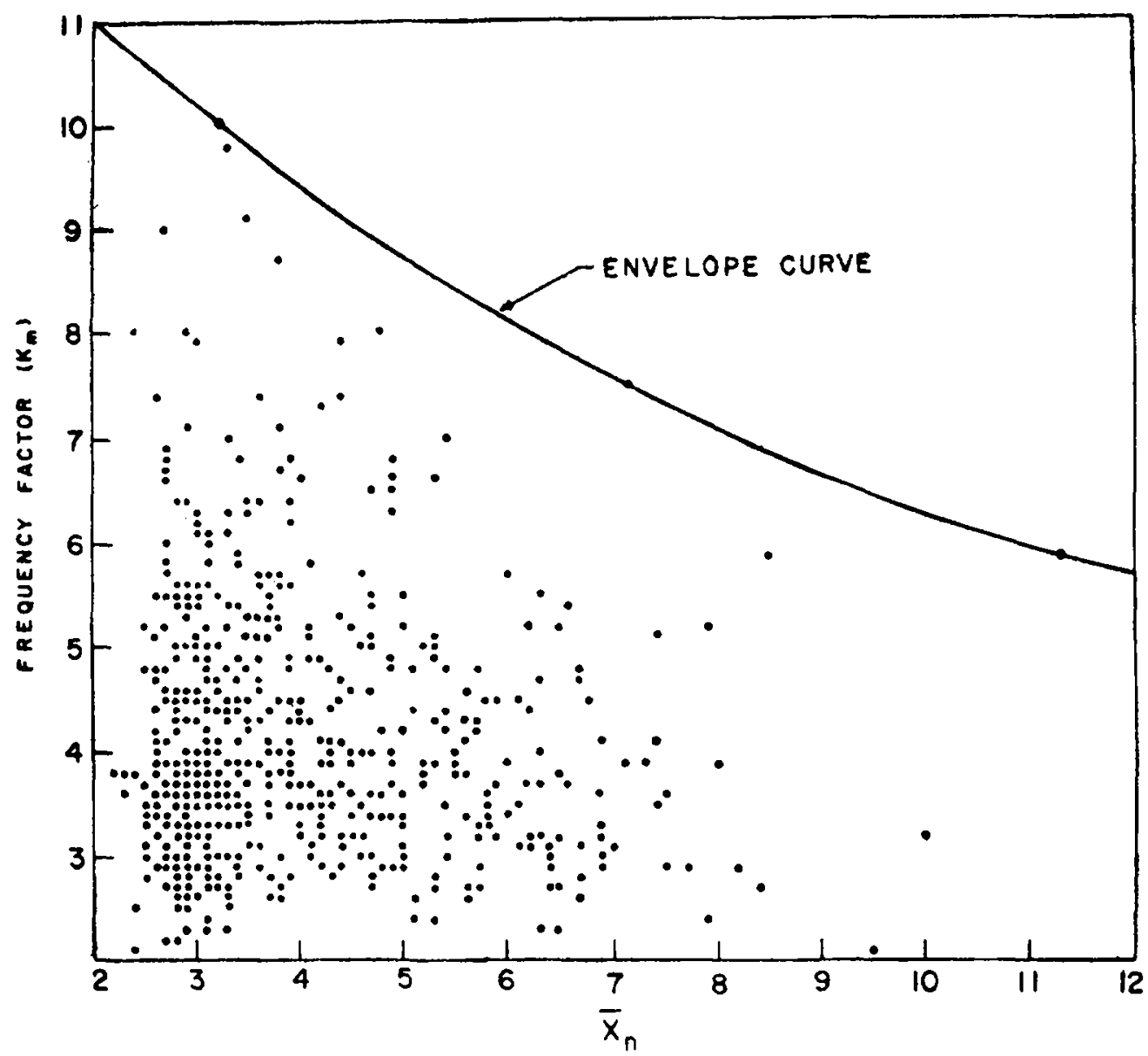

Figure 1. Relationship between frequency factor $\left(K_{m}\right)$ and mean annual maximum rainfall $\left(\bar{X}_{n}\right)$ for onaday reinstorm duration. 
for corresponding values of $\bar{X}_{n}$ of the long-period stations in this region. Using these $K_{m}$ values for each of the stations, PMP values were derived by using (1).

\section{Preparation of a generalized PMP chart}

Before preparing a generalized PMP chart for the southern half of the Indian peninsula, the coefficient of variation $\left[\mathrm{CV}=\left(S_{n} / \bar{X}_{n}\right) \times 100\right]$ values for all the 600 rainfall stations were plotted on a large-scale base map of the region to smooth out the inherently large errors associated with standard deviations (Hershfield 1961). On this map the CV values of nearby stations were compared with one another and wherever necessary the $C V$ values were adjusted and standard deviation values were recalculated. As an example, if in a certain area, the $\mathrm{CV}$ values of different stations were of the order of say 40 to $45 \%$, while an odd station in that area had its $\mathrm{CV}$ value of the order of $65 \%$, then its $\mathrm{CV}$ value was adjusted to about $45 \%$. Using this revised value of $\mathrm{CV}$, the standard deviation $\left(S_{n}\right)$ was recalculated using the original value of $\bar{X}_{n}$ for that station. The revised standard deviation $\left(S_{n}\right)$ values thus obtained were then used to recalculate PMP estimates of those stations whose $\mathrm{CV}$ values were adjusted. Figure 2 shows the isobyetal pattern of one-day (i.e., observation day from 0300 GMT of previous day to 0300 GMT of date) generalized PMP chart. It is seen from this chart (see figure 2) that one-day PMP estimates over the southern half of the Indian peninsula south of lat. $16^{\circ} \mathrm{N}$ range from about 25 to $85 \mathrm{~cm}$.

\section{Discussion of PMP generalized chart}

The isohyetal pattern of PMP over a region, like rainfall, depends upon the physical features or the orography of the region. Figure 2 shows that high values of PMP were obtained along the east and west coasts of the peninsula. Apparently, the high values along and near the west coast are mainly due to the rugged topography of the Western Ghats, while the high values along the east coast are due to the movement and land-fall of cyclonic disturbances from the Bay of Bengal particularly in the post-monsoon months of October to December.

The highest onc-day PMP values of the order of $75 \mathrm{~cm}$ and $85 \mathrm{~cm}$ were obtained for the two rainiest stations of the region, viz., Agumbe and Bhagamandala (Dhar et al 1978) respectively. On 25 July 1924 Bhagamandala, which is known as the Cherrapunji of the peninsular India, recorded the highest one-day rainfall of $84 \mathrm{~cm}$ and it appears that this record rainfall at this station was of near PMP magnitude. It is also seen from figure 2 that the central parts of the peninsula have comparatively low values of PMP of the order of 25 to $40 \mathrm{~cm}$. High PMP values of the order of 45 to $65 \mathrm{~cm}$ have been obtained in Annamali hills and in Tirunelveli District of Tamil Nadu in the southeast of the peninsula.

\section{Unprocedented rainfall over coastal Tamil Nadu}

The southern states of Tamil Nadu, Andhra Pradesh, Kerala and Karnataka receive heavy to very heavy rainfall during the post-monsoon months of October 


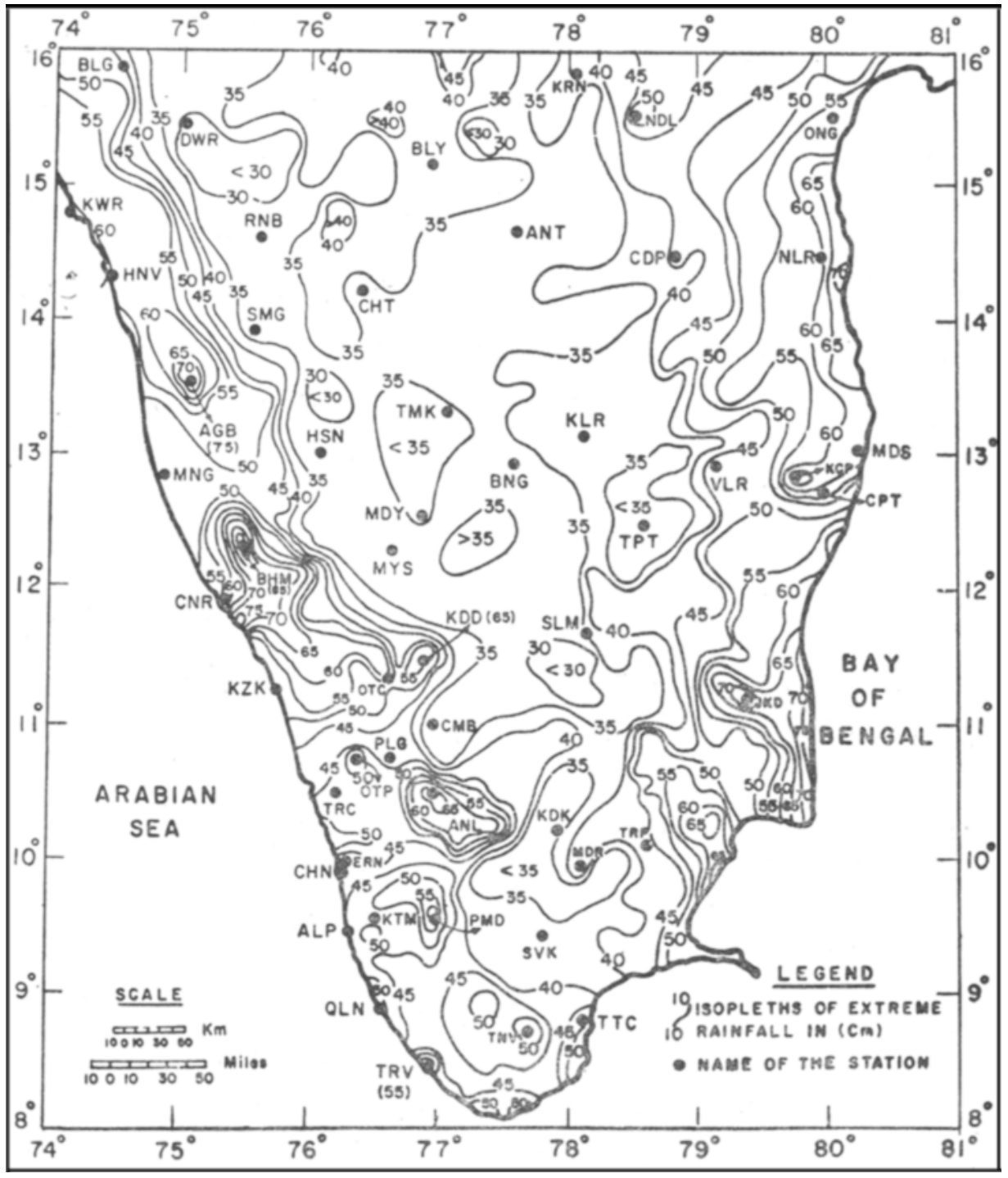

Figure 2. Generalized chart of une-day extreme rainfall (in $\mathrm{cm}$ ) over southern half of Indian penirsula (Lat. $8^{\circ} \mathrm{N}$ to $16^{\circ} \mathrm{N}$ ).

to December in association with the movement of depressions/cyclonic storms in the south Bay of Bengal. After crossing the Tamil Nadu coast these disturbances move in a westerly to northwesterly direction across the peninsula and sometimes re-emerge into the Arabian Sea and get strengthened there due to fresh feed of moist air. Sometimes, these disturbances move in a northerly or north northwesterly direction in the Bay of Bengal very close to the Tamil Nadu-Andhra coasts causing exceptionally heavy rainfall in the coastal areas of Tamil Nadu and Andhra Pradesh. 
In November 1976, exceptionally heavy rain and consequent severe flooding occurred in the coastal districts of Tamil Nadu due to the movement of a deep depression very close to the Tamil Nadu coast between 23 to 27 November. On 25 November several stations in this area received heavy rainfall and it was reported that unprecedented rainfall had occurred over the region.

Figure 2 shows that PMP over the Tamil Nadu coastal region can be of the order of 50 to $65 \mathrm{~cm}$ in a day. Observed l-day rainfall during the November 1976 rainspell were found to be nowhere of that order. Madras city (Nungambakkam Observatory) recorded the highest rainfall of $45 \mathrm{~cm}$ on 25 November 1976 which is nearly $10 \mathrm{~cm}$ less than the PMP estimate for this station. The return period for this rainfall was found to be about 4,500 years. Kaiahasti, located in Chittoor District of Andhra Pradesh, received about $46 \mathrm{~cm}$ of rainfall on this very day and its return period was found to be about 3,700 years. PMP for this station is also of the same order as that of Madras city. Thus, it can be said that the November 1976 rainspell over and near Tamil Nadu coast, though quite heavy, was not of PMP magnitude.

\section{Conclusions}

About 600 long-period rainfall stations, whose daily rainfall data are continuously available for the last 70 to 80 years from 1891 have been used for the preparation of a generalized PMP chart of one-day duration for the southern half of Indian peninsula between lat. $8^{\circ} \mathrm{N}$ to $16^{\circ} \mathrm{N}$. This study has shown that extreme point rainfall over this region can vary from about 25 to about $85 \mathrm{~cm}$ in one-day and stations along and near the western and eastern coasts of the peninsula can have very high values of PMP ranging from 50 to $70 \mathrm{~cm}$ in one-day. In this entire region Bhagamandala, a station in Coorg District of Karnataka, was found to have the highest value of PMP which is of the order of $85 \mathrm{~cm}$. As expected, stations located in the central parts of the peninsula do have the lowest values of PMP of the order of 25 to $35 \mathrm{~cm}$ per day.

Comparing southern peninsular estimates of point PMP with the corresponding north Indian estimates, it was observed that by and large in the north Indian plains, PMP values vary from about 35 to $90 \mathrm{~cm}$ while over the south peninsula these estimates vary from about 25 to $85 \mathrm{~cm}$.

The heavy rainfall received over coastal Tamil $\mathrm{Nadu}$ in association with the cyclonic disturbance of November 1976 was examined and it was found that the rainfali, though quite heavy, was nowhere near the PMP estimates for this region. However, it was observed that the one-day rainfall of two stations [viz, (i) Madras city (Nungambakkam) and (ii) Kalahasti] had rainfall whose return periods were 4,500 and 3,700 years respectively.

\section{Acknawledgements}

Authors are thankful to Dr Bh V Ramana Murthy, Indian Institute of Tropical Meteorology, for his keen interest in hydrometeorological studies. Thanks are also due to Mr G C Ghosh and Mr R B Sangam of the Hydromet Research 
Project for their help in the preparation of this note and to $\mathrm{Mr} V \mathrm{~V}$ Savargaonkar for typing the manuscript.

\section{References}

Bruce J P and Clark R H 1966 Introduction to hydrometeorology (New York: Pergamon Press) p. 233

Chow V T 1951 Trans. Am. Geophys. Union 32231

Dhar O N and Kamte P P 1969 Indian J. Meteorol. Geophys. 2031

Dhar O N and Kamte P P 1971 Indian J. Meteorol. Geophys. 22559

Dhar O N and Kamte P P 1973 Irrig. Power J. 30237

Dhar O N and Kulkarni A K 1970 Flood forecasting control and flood damage protection. Proc. symp. (New Delhi: Central Board of Irrigation and Power) Publication 107, p. 126

Dhar O N, Kulkarni A K and Sangam R B 1975a Hydrol. Sci. Bull. 2061

Dhar O N and Kulkarni A K 1975b Proc. Natl. Symp. Hydrol. (University of Roorkee, India) G12

Dhar O N, Mandal B N and Ghosh G C 1978 Indian J. Power River Val. Dev. 2847

Hershfield D M 1961 J. Hyd. Divn. Am. Soc. Civil Eng. 8799

Hershfield D M $1965 \mathrm{~J}$. Am. Water Works Assoc. 57965

Majumdar K C and Ranga Rajan R 1966 Indian J. Meteorol. Geophys. 17 Splo No. p. 79

Mejia G and Villegas F 1979 Proc. Third Conf. Hydrometeorol. (Boston: Am. Meteor. Soc.) p. 74

Myers V A 1967 WBTM Hydro. (US Weather Bureau) No. 520

Wiesner C J 1970 Hydrometeorology (London: Chapman and Hall) p. 222

Wilson W T 1963 Trans. Am. Soc. Civil Eng. 128 pt. I 552

World Meteorological Organisation 1970 Guide to hydrometeorological practices WMO 168 TP 82 P A. 16

World Meteorological Organisation 1969 Estimation of maximum floods, Technical note No. 98 WMO 233 TP 126 P 78

World Meteorological Organization 1973 Manual for estimation of probable maximum precipitation, WMO No. 332 p. 95

World Meteorological Organisation 1976 The quantitative evaluation of the risk of disaster from tropical cyclones. Special environmental Report No. 8 WMO No. 455 p. 46. 